\title{
SOCIODEMOGRAPHIC AND LIFESTYLE FACTORS AS THE RISK OF DIABETIC FOOT ULCER IN THE UNIVERSITY OF MALAYA MEDICAL CENTRE
}

\author{
Misliza A, Mas Ayu S \\ Department of Social and Preventive Medicine, Faculty of Medicine, University of Malaya, Kuala Lumpur
}

\begin{abstract}
:
A case-control study was conducted between November 2005 and May 2007 in the University of Malaya Medical Centre (UMMC), University of Malaya, Kuala Lumpur, Malaysia. The objective of this study was to identify specific socio-demographic and lifestyle factors which were associated with foot ulcer in Type 1 and Type 2 diabetes patients. There were 125 cases and 250 controls by using universal sampling. Diabetic foot ulcer was defined as "the full thickness skin break at least to Grade 1 Wagner Stage, occurring distal to malleoli". The case was defined as the diabetic patient who was newly diagnosed or who has a known case of diabetic foot ulcer and the control was defined as the diabetic patient without active foot ulcer. Data was collected via face-to-face interview using a structured questionnaire. Results showed that diabetic patients at younger age group, 44 years old and less (OR $5.9095 \% \mathrm{Cl} 2.31,15.10)$, Indian (OR $3.2495 \% \mathrm{Cl} 1.66,6.30$ ), and smoker (OR $3.8595 \% \mathrm{Cl} 1.77,8.35)$ were the independent risk factor for diabetic foot ulcer. (JUMMEC 2009; 12 (1): 15-21)
\end{abstract}

KEYWORDS: diabetic foot ulcer, socio-demographic, lifestyle, risk factor

\section{Introduction}

The World Health Organization (WHO) and International Diabetes Federation (IDF) declared that the diabetic foot problem was a global problem which required prompt actions to be taken quickly (1).

A review has shown that the worldwide annualpopulation based incidence of diabetic foot ulcer ranges from $1.0 \%$ to $4.1 \%$ and the prevalence ranges from $4.0 \%$ to $10.0 \%$ (2). In Malaysia, the prevalence of foot ulceration in patients who were attending a diabetic outpatient clinic was $6.0 \%$ (3). It was also found that $2.8 \%$ of diabetic patients had foot ulcer in Kelantan (4) and that the prevalence of diabetic foot ulcer was $9.7 \%$ in the outpatient setting (5).

There were multiple factors associated with the natural history of foot ulcer in diabetic patients; intrinsic risk factors which included metabolic or biologic characteristic and the extrinsic risk factors which result from the patient's interaction with the environment. Peripheral neuropathy, peripheral vascular disease and foot trauma were the three principle mechanisms in the pathophysiology of foot ulcer and had been well reported by numerous epidemiological studies (610). Socio-demographic and lifestyle factors of diabetic patients were also important as the extrinsic risk factors that contributed to the etiology of ulceration, but the association was inconclusive. However, those factors were used in the foot care education and prevention of foot ulcer $(2,11,12)$. Diabetic patients were encouraged to stop smoking and drinking alcohol, to practice nonweight bearing exercises and to wear proper shoes and maintain the ideal body weight in the prevention of diabetic foot ulcer. Therefore, this study aimed to identify the specific socio-demographic and lifestyle factors associated with diabetic foot ulcer..

\section{Methodology}

This case-control study was conducted at the University of Malaya Medical Centre (UMMC), Kuala Lumpur, Malaysia, between November 2005 and May 2007.

\section{Correspondence:}

Misliza Ahmad

Department of Social and Preventive Medicine

Faculty of Medicine, University of Malaya

50603 Kuala Lumpur

Email: mislizahmad@yahoo.com 
The case was defined as the diabetic patient (Type 1 and Type 2 ) who was newly diagnosed or who has a known case of diabetic foot ulcer, and who was attended to at the Diabetic Foot Care and Wound Management, UMMC. The control was defined as the diabetic patient without active foot ulcer, who was attended to at the Family Clinic, Primary Care Medicine Department, UMMC. Diabetic foot ulcer was defined as the full thickness skin break at least to Grade 1 Wagner Stage, occurring distal to malleoli (13).

The minimum sample size was calculated using Epi Info Version 6 based on the 95\% confidence interval, $80 \%$ power of study, prevalence of smokers in Malaysia of $24 \%$ (14), OR of 2.0 and ratio of $1: 2$ for case and control. A total of 375 respondents which consisted of 125 cases and 250 controls were included in this study. A universal sampling was used in the recruitment of respondents.

Face-to-face interview was carried out using a structured questionnaire which was pre-tested prior to the study. The sociodemographic variables were age, gender, ethnic, marital status, living status, educational level, occupation type and household income per month. Lifestyle factors include body mass index, smoking status, duration of smoking, number of cigarette per day, status of alcohol

Table 1: Univariate analysis of sociodemographic factors between cases and controls

\begin{tabular}{|c|c|c|c|c|}
\hline Variables & Cases $(n=125)$ & Controls $(n=250)$ & Crude OR (95\% CI) & p value \\
\hline \multicolumn{5}{|l|}{ 1.Age of respondents (years) } \\
\hline Mean \pm s.d & $55.9 \pm 9.3$ & $62.5 \pm 9.3$ & $0.93(0.91,0.95)$ & 0.001 \\
\hline$\geq 65$ & $24(17.9)$ & $110(82.1)$ & 1.00 & 0.001 \\
\hline $55-64$ & $46(33.6)$ & $91(66.4)$ & $2.32(1.32,4.08)$ & \\
\hline $45-54$ & $39(50.0)$ & $39(50.0)$ & $4.58(2.45,8.57)$ & \\
\hline$\leq 44$ & $16(61.5)$ & $10(38.5)$ & $7.33(2.97,18.13)$ & \\
\hline \multicolumn{5}{|l|}{ 2. Gender } \\
\hline Male & $61(26.6)$ & $168(73.4)$ & 1.00 & 0.001 \\
\hline Female & $64(43.8)$ & $82(56.2)$ & $2.15(1.39,3.33)$ & \\
\hline \multicolumn{5}{|l|}{ 3. Ethnic } \\
\hline Chinese & $15(16.3)$ & $77(83.7)$ & 1.00 & 0.001 \\
\hline Malay & $38(34.2)$ & $73(65.8)$ & $2.67(1.36,5.26)$ & \\
\hline Indian & $72(41.9)$ & $100(58.1)$ & $3.70(1.97,6.94)$ & \\
\hline \multicolumn{5}{|l|}{ 4. Marital status } \\
\hline Married & $102(35.8)$ & $183(64.2)$ & 1.00 & 0.074 \\
\hline Unmarried & $23(25.6)$ & $67(74.4)$ & $0.62(0.36,1.05)$ & \\
\hline \multicolumn{5}{|l|}{ 5. Living status } \\
\hline Living with spouse/relative/others & $121(33.1)$ & $245(66.9)$ & 1.00 & 0.474 \\
\hline Alone & 4 (44.4) & $5(55.6)$ & $1.62(0.43,6.14)$ & \\
\hline \multicolumn{5}{|l|}{ 6. Educational level } \\
\hline Tertiary & $13(71.7)$ & $33(28.3)$ & 1.00 & 0.647 \\
\hline Secondary & $57(66.3)$ & $112(33.7)$ & $1.29(0.63,2.65)$ & \\
\hline Primary & $48(36.1)$ & $85(63.9)$ & $1.43(0.69,2.98)$ & \\
\hline Never schooling & $7(25.9)$ & $20(74.1)$ & $0.89(0.30,2.60)$ & \\
\hline \multicolumn{5}{|l|}{ 7. Household income per month (RM) } \\
\hline More than 3000 & $30(36.6)$ & $52(63.4)$ & 1.00 & 0.499 \\
\hline 2000 to 2999 & $26(37.7)$ & $43(62.3)$ & $1.05(0.54,2.03)$ & \\
\hline 1000 to 1999 & $44(33.1)$ & $89(66.9)$ & $0.86(0.48,1.53)$ & \\
\hline Less than 1000 & $25(27.5)$ & $66(72.5)$ & $0.66(0.35,1.25)$ & \\
\hline \multicolumn{5}{|l|}{ 8. Occupation type } \\
\hline Unemployed & $70(26.8)$ & $191(73.2)$ & 1.00 & 0.001 \\
\hline Professional /non-manual & $27(45.0)$ & $33(55.0)$ & $2.23(1.25,3.98)$ & \\
\hline Manual workers & $28(51.9)$ & $26(48.1)$ & $2.94(1.61,5.35)$ & \\
\hline
\end{tabular}

Data are $n(\%)$ and mean $\pm S D$ 
consumption, duration of alcohol intake, number of drinks per week, exercise practice, type of exercise and type of foot wear during exercise.

Ethical approval from UMMC and permission from the Head of Rehabilitation Department and the Head of Primary Care Department were obtained prior to the study. Verbal and written consent from the patients were obtained also. All the information was kept confidential.

The data was entered and analyzed using Statistical Package for Social Sciences (SPSS) version 12.5. Descriptive and inferential analyses were performed. Continuous variables were summarized as mean and standard deviation. Median and range were used to describe data with skewed distribution. Categorical variables were summarized into frequency and proportion. In the comparison of cases and controls, student $t$-test was used for normal distribution continuous data. A Mann Whitney test was used if the data was skewed. Categorical data was analyzed with Chi-Square test and Fisher's exact test. Significant level was preset at 0.05 and $95 \%$ confidence interval was reported with crude and adjusted odds ratio. Multivariate Logistic Regression was used to determine the independent predictors of diabetic foot ulcer. All variables with $p<0.25$ and biological plausible were entered for multivariate analysis. The final model included all variables with $p<0.05$ and concluded based on the principle of Parsimony.

\section{Results}

\section{Socio-demographic factors}

Table 1 shows the distribution and association of sociodemographic factors with diabetic foot ulcer. Age, gender, ethnic and occupation type were found to be significantly different in the proportion between cases and controls and significantly associated with diabetic foot ulcer $(p=0.001)$.

The controls were significantly older than the cases, with the mean age in the cases as $55.9 \pm 9.3$ years old and the controls as $62.5 \pm 9.3$ years old. The crude OR was increasing with decreasing age. Patients at age 44 and younger had 7.33 times risk of having diabetic foot ulcer compared to patients at age 65 and above $(95 \% \mathrm{Cl} 2.97,18.13)$
Females were more in the control group (73.4\%) while the proportion of males were slightly higher in the case group (51.2\%). The odds of having diabetic foot ulcer in males were 2.15 times more than females $(95 \% \mathrm{Cl}$ $1.39,3.33)$.

In ethnic distribution, $83.7 \%$ of the patients in the control group were Chinese and only $16.3 \%$ of them were in the case group. Both Malay and Indian distributions were also higher in the control group. Malay patients had a 2.67 times higher risk $(95 \% \mathrm{Cl}$ $1.36,2,56)$ and Indian patients had 3.70 times higher risk $(95 \% \mathrm{Cl} 1.97,6.94)$ of having diabetic foot ulcer compared to the Chinese patients.

Unemployed persons were the majority in the control group $(76.4 \%)$ compared to the cases $(26.8 \%)$. The proportion of professionals and non-manual workers was slightly higher in the control group (55.0\%) and the proportion of manual workers were almost equal in both groups. The odds of having diabetic foot ulcer in the professional and non- manual workers were 2.23 times $(95 \% \mathrm{Cl} 1.25,3.98)$ compared to the unemployed. The manual workers had a higher risk of developing diabetic foot ulcer with crude OR of 2.94 (95\% Cl 1.61, 5.35).

\section{Lifestyle factors}

Table 2 shows the distribution and association of lifestyle factors with diabetic foot ulcer. Smoking as a factor showed significant statistical association with diabetic foot ulcer. The distribution and association of other lifestyle factors were not significant.

The proportion of current smoker was higher in the case group (63.9\%) compared to the control group $(36.1 \%)$ and were significantly different $(p=0.001)$. The odds of having diabetic foot ulcer in smokers were 4.11 times more than non-smokers $(95 \% \mathrm{Cl}: 2.00$, 8.43).

\section{Independent risk factors}

Table 3 shows the independent risk factors of diabetic foot ulcer after using multivariate analysis. In the final model of logistic regression, age group, ethnic and smoking statuses were significantly associated with diabetic foot ulcer. Patients at age 44 and younger were 5.90 times $(95 \% \mathrm{Cl} 2.31,15.10)$ more likely to have diabetic foot ulcer compared to the patients at 
Table 2: Univariate analysis of lifestyle factors between cases and controls

\begin{tabular}{|c|c|c|c|c|}
\hline Variables & Cases $n=125$ & Controls $n=125$ & Crude OR ( $95 \% \mathrm{CI})$ & p value \\
\hline \multicolumn{5}{|l|}{ 1.Body Mass Index } \\
\hline $18.5-22.9$ & $24(32.4)$ & $50(67.6)$ & 1.0 & $0.854 ¥$ \\
\hline$\geq 23.0$ & $101(33.6)$ & $200(66.4)$ & $1.05(0.61,1.81)$ & \\
\hline \multicolumn{5}{|l|}{ 2. Smoking status } \\
\hline Smoker & $102(30.1)$ & $237(69.9)$ & 1.0 & $0.001 ¥$ \\
\hline Non-smoker & $23(63.9)$ & $13(36.1)$ & $4.11(2.00,8.43)$ & \\
\hline \multicolumn{5}{|l|}{ 3. No of cigarette per day ${ }^{a}$} \\
\hline 1 to 10 (Light) & $8(53.3)$ & $7(46.7)$ & 1.0 & $0.480^{*}$ \\
\hline 11 to 20 (Moderate) & $7(77.8)$ & $2(22.2)$ & $3.06(0.47,19.88)$ & \\
\hline$\geq 21$ (Heavy) & $8(66.7)$ & $4(33.3)$ & $1.75(0.36,8.42)$ & \\
\hline \multicolumn{5}{|l|}{ 4. Duration of smoking a } \\
\hline 10 years and below & $2(66.7)$ & $1(33.3)$ & 1.0 & $0.917^{*}$ \\
\hline 11 years and above & $21(63.6)$ & $12(36.4)$ & $0.81(0.03,13.41)$ & \\
\hline \multicolumn{5}{|l|}{ 5. Status of alcohol intake } \\
\hline Non-drinker & $109(32.5)$ & $226(67.5)$ & 1.0 & $0.344 ¥$ \\
\hline Current drinker & $24(60.0)$ & $16(40.0)$ & $1.38(0.71,2.71)$ & \\
\hline \multicolumn{5}{|l|}{ 6. Number of drinks per week ${ }^{b}$} \\
\hline 1 to 3 (Light drinker) & $6(85.7)$ & $1(14.3)$ & 1.0 & $0.501 *$ \\
\hline 4 to 14 (Moderate drinker) & $2(66.7)$ & $1(33.3)$ & $0.33(0.01,8.18)$ & \\
\hline \multicolumn{5}{|l|}{ 7. Duration of alcohol intake ${ }^{b}$} \\
\hline Below 10 years & $1(50.0)$ & $1(50.0)$ & 1.0 & $0.272^{*}$ \\
\hline 11 years and above & $7(87.5)$ & $1(12.5)$ & $7.00(0.22,226.0)$ & \\
\hline \multicolumn{5}{|l|}{ 8. Exercise } \\
\hline Do exercise & $39(29.8)$ & $92(70.2)$ & 1.0 & $0.284 ¥$ \\
\hline Do not exercise & $86(35.2)$ & $158(64.8)$ & $1.28(0.81,2.03)$ & \\
\hline \multicolumn{5}{|l|}{ 9. Type of exercise ${ }^{c}$} \\
\hline Non weight bearing & $8(24.2)$ & $25(75.8)$ & 1.0 & $0.423 ¥$ \\
\hline Weight bearing & $31(24.8)$ & $67(68.8)$ & $1.45(0.59,3.57)$ & \\
\hline \multicolumn{5}{|l|}{ 10. Footwear during exercise ${ }^{c}$} \\
\hline Sport shoes & $18(25.7)$ & $52(74.3)$ & 1.0 & $0.278 ¥$ \\
\hline Other than sport shoes & $21(34.4)$ & $40(65.6)$ & $1.52(0.72,3.22)$ & \\
\hline
\end{tabular}

Data are n (\%)

${ }^{a}$ analysis among the smokers case $=23$ control $=13$

${ }^{b}$ analysis among the regular drinker case $=8$ control $=2$

\# Pearson chi-square

c analysis among respondents who exercise case $=39$ control $=92$

* Fisher exact test

age 65 and above. The risk decreases with increasing age. The odds ratio in patients at age 45 to 54 was 4.66 (95\% Cl 2.42, 8.98) but decreased to 2.46 (95\% $\mathrm{Cl} 1.36,4.46)$ in patients at age 55 to 64 . The Indian patients had the highest risk of developing diabetic foot ulcer and a 3.24 times higher risk (95\% Cl 1.66, 6.30) compared to the Chinese. Malay patients also had the risk of diabetic foot ulcer with odds ratio of 2.20 (95\% Cl 1.08, 8.47). The odds of developing diabetic foot ulcer in the smokers were 3.85 times higher $(95 \% \mathrm{Cl} 1.77,8.35)$ compared to the nonsmokers.

\section{Discussion}

Our findings showed that the younger patients had a higher risk of develop diabetic foot ulcer compared to the elderly patients. The same finding was also found in another study $(13,15)$. However, age was inconclusive as the predictor of diabetic foot ulcer (16, $19)$.

This finding contradicted with the theory that the risk was higher among the older age group. The elderly patients were presumed to be more at risk due to the development of complications such as peripheral 
Table 3: Independent predictors of diabetic foot ulcer after the multivariate analysis (Final model)

\begin{tabular}{lcc}
\hline Predictors & Adjusted OR & 95\% Cl \\
\hline $\begin{array}{l}\text { 1. Age group (years) } \\
\quad \text { } 65\end{array}$ & 1.00 & \\
$55-63$ & 2.46 & $1.36,4.46$ \\
$45-54$ & 4.66 & $2.42,8.98$ \\
$\quad \leq 44$ & 5.90 & $2.31,15.10$ \\
2. Ethnic & & \\
$\quad$ Chinese & 1.00 & \\
Malay & 2.20 & $1.08,8.47$ \\
Indian & 3.24 & $1.66,6.30$ \\
3. Smoking status & & \\
$\quad$ Non smoker & 1.00 & \\
$\quad$ Smoker & 3.85. & $1.77,8.35$ \\
\hline
\end{tabular}

* Adjusted with gender, marital status, living status, educational level, household income per month, occupation type, body mass index, no. cigarette per day, duration of smoking, alcohol, no. of drinks per week, duration of alcohol intake, exercise, type of exercise, footwear during exercise

neuropathy, peripheral vascular disease and visual impairment when the age advances $(20,21)$. Possible reasons as to why the elderly patients had lesser risk of diabetic foot ulcer are probably due to the fact that most of them were unemployed, less mobile and less exposed to the potential trauma to the foot compared to the younger age group (13). Another possible cause of this finding could be due to the imbalanced proportion of patients in elderly age group and younger age group. This study had a large number of patients at age 65 years old and above and $82.1 \%$ of them did not develop foot ulcer, compared to only 26 patients at the age 44 and below and $61.5 \%$ of them had diabetic foot ulcer. It appears that the elderly patients in this study were healthier and protected from diabetic foot ulcer.

The possibility of biasness in the study site of cases recruitment should be considered. In this study, the cases were recruited at the outpatient Diabetic Foot Clinic.

Smoking was inconclusive as the independent risk factor for diabetic foot ulcer by previous studies $(17,18,22,23)$. In this study, smoking is significantly linked to diabetic foot ulcer. The same finding was demonstrated by another study in the Netherlands (24). Possible explanations as to why smoking was a risk for diabetic foot ulcer could be due to its impact to the development of neuropathy, peripheral vascular disease (PVD) and retinopathy which could lead to the occurrence of foot ulcer in the diabetic patients.

Smoking was a documented risk factor for both development and progression of neuropathy in diabetic patients. Smoking was also found to be associated with retinopathy but less constantly (25). Smoking will cause the arteries to constrict and become narrower and it also makes the platelet clump together and lead to atherosclerosis and finally PVD (26).

Indians was found to have the highest risk in the development of diabetic foot ulcer followed by Malays. The proportion of diabetes was highest among the Indians, therefore they were also exposed to the risk of diabetic foot ulcer (14).

The role of ethnic differences in causing the risk of diabetic foot ulcer is still unclear as it may be due to differences in cultural, behavioral, socioeconomic or physiological factors. The ethnic factor had been demonstrated by other studies $(16,27)$. In fact, Abbot et al found that Asians and African Caribbean had significantly lower prevalence of diabetic foot ulcer compared to the European (27). The explanation given was that there were lower proportion of peripheral arterial disease, neuropathy, insulin usage and foot deformities among Asians and African Caribbeans. They were found to have lower level of neuropathy. As such, further study should be conducted to determine the factors associated with foot ulcer among the Indian diabetic patients.

Findings in a cohort study found that high body weight was found to be the predictor for diabetic foot ulcer (13). However, high body weight was not a consistent predictor as other studies found it not to be significant $(8,24,32,35,36)$. The possible mechanism for the association of high body weight and the foot ulcer was that higher foot pressure was found in heavier patients (13). High plantar pressure was one of the predictor of diabetic foot ulcer $(8,30)$. However, high body mass was a poor predictor of peak plantar pressure.

Studies have shown that the correlation between body mass and plantar pressure to be statistically significant but the functional relationship was weak $(28,29)$. This study failed to demonstrate high body weight as a risk factor of foot ulcer. 
Findings from another cohort study found that daily alcohol intake was one of the predictors in diabetic foot ulcer (30). High alcohol consumption has toxic effect on the nerve tissue and eventually neuropathy develops (alcoholic neuropathy) and increases the risk of diabetic foot ulcer (26). However, alcohol consumption was not a significant factor in other studies $(18,22,23)$, where negative correlation between alcohol consumption and diabetic foot ulcer were found.

Exercise was an important component of diabetes management that can help maintain physical fitness, reduce the glucose level and maintain the body weight of patient. Exercise can also help to prevent the peripheral neuropathy development by reviving motor nerve function and preserving unaffected motor nerve. Exercise is highly recommended as part of diabetic management, together with a healthy diet and pharmacological intervention $(31,32)$.

However, weight-bearing exercise (a physical activity in which legs and feet bear all the weight, as example walking, jogging, treadmill and others) or wearing inappropriate footwear during exercise could cause abnormal foot pressures, inadequate blood flow or ischemia, and inflammation from repetitive stress that may result in wounds and ulcers. Non-weight bearing exercises such as swimming, cycling, and upper body exercise are recommended for diabetic patients, especially those who have lost their protective sensation (32).

We found all those factors related with exercise not significantly associated with diabetic foot ulcer. Even with these negative findings, diabetic patients should have proper consultation with their physicians on exercise to prevent the occurrence of foot ulcer.

\section{Conclusions and Recommendations}

Young diabetic patients, smoking, being of Malay or Indian ethnicity were the independent risk factors for diabetic foot ulcer. Therefore, these factors should be considered when screening is done among diabetic patients.

Foot care education should be emphasized in Indian patients as the risk of having foot ulcer was higher compared to Malay and Chinese patients. Screening and foot education should be given to all the diabetic patients regardless of their age. Diabetic patients at the age 55 and less were the productive age group who are mostly involved in the work sectors and were more mobile. Therefore, although the protective sensation of their feet were still intact, they were exposed to repetitive stress and feet trauma. All diabetic patients who are currently smoking should be referred to the smoking cessation programme such as the Quit Smoking Clinic. The awareness of the complications to smoking should always be delivered to the diabetic patients.

\section{References}

1. World diabetes day 2005. http://www. worlddiabetesday.org/the_campaign/pages $/ 60_{\text {_ }}$ world_diabetes_day_2005. 16 February 2008.

2. Singh N, Armstrong DG, Lipsky BA. Preventing foot ulcers in patients with diabetes. JAMA 2005; 293: 217-228.

3. Ministry of Health Malaysia. Clinical Practice Guidelines. Management of Diabetic Foot. Ministry of Health Malaysia. Academy of Medicine, Malaysia. 2004.

4. NorF, Sulaiman S. A review of diabetic complications among poorly controlled diabetes at 8 health clinics in Kelantan. NCD Malaysia 2004; 3: 13-16.

5. Mimi O, Teng $\mathrm{CL}$. The prevalence of diabetic peripheral neuropathy in an outpatient setting. Med J Mal 2003; 58: 533-538.

6. Frykber RG. Diabetic foot ulceration. In: Frykberg RG, ed. The High Risk Foot in Diabetes Mellitus. New York: Churchill Livingstone; 1991: 151-195.

7. Frykberg RG, Armstrong DG, Giurini J, et al. Diabetic foot disorders. A clinical practice guideline. $J$ Foot Ankle Surgery 2000; 39 (Suppl): S1-S60.

8. Laing P. The development and complication of diabetic foot ulcers. Am J Surg 1998;176 (Suppl 2A): S11-S16.

9. Boulton AJM. The pathogenesis of diabetic foot problems: an overview. Diabet Med 1995; 13 (Suppl): S12-S16.

10. Reiber GE, Vileikyte L, Boyko EJ, et al. Causal pathways for incident lower extremity ulcers in 
patients with diabetes from two settings. Diabetes Care 1999; 22:157-162.

11. American Diabetes Association. Preventive foot care in Diabetes. Diabetes Care 2004; 27 (Suppl): S63-S64.

12. Jones R. Exploring the complex care of the diabetic foot ulcer. JAAPA 2006; 19: 31-36.

13. Abbot $C A$, Carrington $A L$, Ashe $H$, et al. The NorthWest Diabetes Foot Care Study: incidence of, and risk factors for, new diabetic foot ulceration in a community-based patient cohort. Diabet Med 2002; 19: 377-384.

14. Institute of Public Health. National Health and Morbidity Survey 1996. Ministry of Health Malaysia 1997.

15. Abbot CA, Vileikyte L, William S, et al. Multicenter study of the incidence of and predictive risk factor for diabetic neuropathic foot ulceration. Diabetes Care 1998; 21: 1071-1075.

16. Frykberg RG. Peripheral neuropathy and high foot pressure in diabetic foot ulceration. Diabetes Care 1998; 21: 1714-1718

17. Boyko EJ, Ahroni JH, Stensel V, et al. A prospective study of risk factors for diabetic foot ulcer: The Seattle Diabetic Foot Study. Diabetes Care 1999; 22: 1036-1042.

18. Sriussadaporn $P$, Mekanadha $P$, Vannasaeng $S$, et al. Factors associated with diabetic foot ulceration in Thailand: a case-control study. Diabet Med 1997; 14: 50-56.

19. Pham H, Armstrong DG, Harvey $C$, et al. Screening techniques to identify people at high risk for diabetic foot ulceration. A prospective multicenter trial. Diabetes Care 2000; 23: 606-611.

20. Millington JT, Ellenzweig JM. Management and treatment of diabetic wounds in the elderly. Ann Long Term Care 2003; 11: 26-32.

21. Fletcher AK, Dulben J. A hospital survey of the care of elderly patients with diabetes mellitus. Age
Ageing 1996; 25: 349-352.

22. McNeely MJ, Boyko EJ, Ahroni JH. The independent ontribution of diabetic neuropathy and vasculopathy in foot ulceration. How great are the risk? Diabetes Care 1995; 18:216-219.

23. Larvey La, Armstrong DG, Vela SA, et al. Practical criteria for screening patients at high risk for diabetic foot ulceration. Arch Intern Med 1998; 158: 157-162.

24. Sonnavaille JJJ, Colly LP, Wikjel D. The prevalence and determinants of foot ulceration in Type II diabetic patients in a health care setting. Diabetes Res Clin Pract 1997; 39: 149-156.

25. Josha DH, Glasgow RE, Tibbs TL. Smoking and diabetes. Diabetes Care 1999; 22: 1887-1898.

26. Peripheral vascular disease. http://www.geocities. com/lungdoctor_tn/Peripheral_Vascular_Disease. htm. 20 Sept. 2005.

27. Abbot CA, Garrow AP, Carrington AL, et al. Foot ulcer risk is lower in South-Asian and African Carribean compared with European diabetic patients in the UK: The North West Diabetes Foot Care Study. Diabetes Care 2005; 28: 1869-75.

28. Schie CHM, Boulton AJM. The effect of arch height and body mass on plantar pressure. Wounds 2000; 12:88-95.

29. Cavanagh PR, Sims DS, Sanders LJ. Body mass is a poor predictor of peak plantar pressure in diabetic man. Diabetes Care 1991; 14: 750-755.

30. Kastenbauer T, Sauseng S, Sokol G, et al. A prospective study of predictors for foot ulceration in Type 2 diabetes. J Am Podiatr Med Assoc 2001; 91: 343-350.

31. Sigal RJ, Kenny GP, Wasserman DH. Physical activity, exercise and Type 2 diabetes. Diabetes Care 2004; 27:2518-2540.

32. Ward SA. Diabetes, exercise, and foot care: Minimizing risks in patients who have neuropathy. Physician and Sports Medicine 2005; 33: 33-39. 